\title{
Selection of hybrid vehicle for green environment using multi-attributive border approximation area comparison method
}

\author{
Tapas Kumar Biswas ${ }^{\mathrm{a}^{*}}$ and Manik Chandra Das ${ }^{\mathrm{a}}$
}

${ }^{a}$ Automobile Engineering Department, MCKV Institute of Engineering, Liluah, Howrah-711204, India

\begin{tabular}{l}
\hline C H R O N I C L E \\
\hline Article history: \\
Received: April 26, 2017 \\
Received in revised format: Sep- \\
tember 26, 2017 \\
Accepted: November 18, 2017 \\
Available online: \\
November 18, 2017 \\
\hline Keywords: \\
Hybrid cars (HEVS) \\
MCDM \\
MABAC \\
Entropy \\
Ranking \\
Sensitivity analysis
\end{tabular}

\section{A B S T R A C T}

\begin{abstract}
The mobility sector including all kinds of transportation systems are facing global challenges in respect of green environmental issues. There has been a paradigm shift in the concept of design and manufacturing of automotive vehicles keeping in mind the scarcity of fossil fuel and the impact of emission on environment due to burning of it. The addition of hybrid and electric vehicles in passenger car segment has got significant momentum to address the global challenges. This research investigates the performance of a group of hybrid vehicles from customers' perspective. Among the different brands that are available in the hybrid vehicle market, smart customers have given priority to vehicle cost, mileage, tail pipe emission, comfortness and high tank size volume for long drive. Considering these attributes, selection strategy for hybrid vehicles has been developed using entropy based multi-attributive border approximation area comparison (MABAC) method. This research highlights the best hybrid vehicle which reduces air pollution in cities with other significant environmental benefits, reduces dependence on foreign energy imports and minimizes the annual fuel cost.
\end{abstract}

\section{Introduction}

The emission of greenhouse gas (GHG) such as $\mathrm{CO}_{2}$ (Carbon di-oxide) and other vehicle pollutants, is putting big challenge before the transportation sector. The Paris Agreement (November, 2016) settles the objective of controlling the increase in the global average temperature in this century well below $2^{0} \mathrm{C}$ above preindustrial levels and pursuing efforts to limit the temperature increase even further to $1.5^{\circ} \mathrm{C}$ (United Nations Framework Convention on Climate Change). Therefore, the problem of global warming can be controlled by introduction and promotion of hybrid vehicles which decrease the emission of exhaust gases into the environment. A hybrid vehicle uses two or more separate power supply such as conventional internal combustion engine with an electric propulsion system (Wirasingha \& Emadi, 2011; Bradley \& Frank, 2009; Morrow et al., 2008; Rahmanet al., 2016). For the presence of electric power train, hybrid vehicles achieve better fuel economy than conventional vehicle. The parallel hybrid electric vehicles (HEVs) can improve fuel economy up to $40 \%$ with respect to conventional

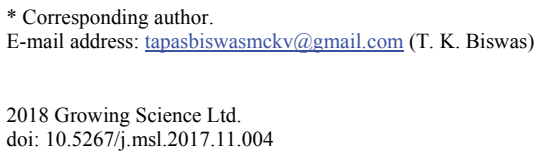


vehicle model (Ganji et al., 2010). HEVs reduce the fuel consumption significantly, improve the standard driving cycle and decrease the emission from tail pipe (Al-Samari, 2017). The dual power helps to maintain the most efficient energy consumption during all driving condition (city and highway) as the car is able to utilize the battery powered engine when driving at lower speed or in traffic, little or no fuel is needed during these conditions. Therefore $\mathrm{HEVs}$ produce $25 \%$ to $30 \%$ less of $\mathrm{CO}_{2}$ emission than regular cars, because it recharges the battery via conventional engine. To sustain into the future we need to optimize energy efficiency across the entire power transmission of vehicle. Kahn (2007) evaluates the performance of hybrid vehicle in respect of environmental quality. Being eco- friendly, the government of several countries offers some tax benefit or incentive to buy this kind of vehicle (Sallee, 2011). Beresteanu and $\mathrm{Li}$ (2011) and Chandra et al. (2010) also find significant effects from gasoline prices and tax incentives on consumer hybrid purchase decision. The effects of local incentives, rising of fuel prices and state sales tax waivers are most strongly associated with hybrid vehicle adoption (Gallagher \& Muehlegger, 2011). De Haan et al. (2006) use Swiss data on buyers of the Toyota Prius model to test for evidence of two rebound effects from its purchase. Hybrid buyers could have switched from already fuel efficient cars to the Prius, or average vehicle ownership could increase. Thus, the number of HEVs elevates quickly in automobile markets (Ganji et al., 2010).

The market of hybrid vehicle has been increasing rapidly during the last decade. Therefore, it has become a decision making problem to the customers to choose the appropriate hybrid car considering several criteria which may be conflicting in nature. The selection of HEV becomes critical for the customer due to availability of many brands with variety of models and features. There are many multiple criteria decision making (MCDM) methods available for selection and ranking of the alternatives. This paper presents the application of multi attributive border approximation area comparison (MABAC) for the selection of hybrid car. This technique provides a basis for decision-making processes where there are limited numbers of choices but each has large number of attributes. In this paper, we consider five criteria which are car model cost, EPA rated combined fuel economy, tank size, tail pipe emission and passenger volume.

It is important to note that smart consumers do not always make their purchasing decisions using structured cost comparison methods, they are concern with new technologies that inherently increase the fuel efficiency and reducing dependence on foreign energy imports as well as achieving better air quality.

The aim of this paper is to choose the best alternative hybrid vehicle which can reduce foreign energy imports and give the green environment to the future. Here, Ford $\mathrm{C}$ max hybrid plug-in, Honda accord hybrid, Honda CR-Z hybrid CVT, Infinity Q70 hybrid, Lexus city hybrid $200 \mathrm{H}$, Toyota Camry hybrid LE, Toyota Prius, VW Jetta hybrid, Chevy Malibu hybrid have been chosen as alternatives for selection and ranking under passenger car category. These alternatives are coded as HEV1 to HEV9 respectively in the remaining part of this paper.

The paper is organized as follows: Section 2 describes application procedure of the proposed model used in the paper. Section 3 gives information about data and computation. A sensitivity analysis has been given in section 4 . Section 5 summarizes the discussion. In the last section conclusion is given.

\section{Research Design}

\subsection{Selection of evaluation criteria}

In multi-criteria environment, performance of alternatives in absolute sense is very difficult to measure. A lot of criteria/factors/attributes exist that affect the performance. All nine HEVs which are chosen for comparison are similar enough to be compared. For the purpose of performance evaluation of hybrid vehicles five criteria namely, EPA rated combined fuel economy, tank size, tail pipe emission, 
passenger volume and vehicle cost have been chosen with the help of expert committee. A brief description of the criteria is presented in Table 1.

\subsection{Importance of criteria}

The performance evaluation criteria mentioned above are conflicting in nature. Out of five criteria, first two and fourth i.e. EPA rated combined fuel economy, tank size and passenger volume are beneficial criteria, i.e. higher the better type. Remaining two are non-beneficial criteria. In this present research Entropy based technique has been used to determine the relative importance of the criteria.

\section{Table 1}

Description of the criteria

\begin{tabular}{|c|c|c|}
\hline $\begin{array}{l}\text { Sl. } \\
\text { No. }\end{array}$ & Criteria & Brief description \\
\hline 1 & $\begin{array}{l}\text { EPA rated Com- } \\
\text { bined } \\
\text { fuel economy }\left(\mathrm{C}_{1}\right)\end{array}$ & $\begin{array}{l}\text { Combined fuel economy is calculated as weighted average of city and highway mile per gallon (MPG) } \\
\text { values. MPG represents the number of miles the vehicle can go consuming one gallon fuel. For city } \\
\text { and highway, } 55 \% \text { and } 45 \% \text { weights are chosen. It is the most prominent factor for comparing vehicles. }\end{array}$ \\
\hline 2 & Tank size (C2) & $\begin{array}{l}\text { It indicates the maximum distance the car can travel between two subsequent full refilling and it is } \\
\text { expressed in gallon. }\end{array}$ \\
\hline 3 & $\begin{array}{l}\text { Tailpipe Emissions } \\
\text { (C3) }\end{array}$ & $\begin{array}{l}\text { It is the quantity of exhaust gas coming out from the vehicle through tail pipe. It is expressed in terms } \\
\text { of tons per hour. }\end{array}$ \\
\hline 4 & $\begin{array}{l}\text { Passenger volume } \\
\text { (C4) }\end{array}$ & $\begin{array}{l}\text { It indicates the space provided for passengers inside the car. More passenger volume means more seat- } \\
\text { ing areas. It is expressed in } \mathrm{ft}^{3} \text {. }\end{array}$ \\
\hline 5 & Vehicle cost (C5) & It is the selling price of vehicle. It is a big concern for customers. \\
\hline
\end{tabular}

\subsection{The Proposed model}

Multiple criteria decision making models are widely used for selecting and prioritizing the alternatives in a set. There are many methods to assess the relative importance of factors or criteria such as eigenvector method, weighted least square method, entropy method, and linear programming technique for multidimensional analysis of preference (LINMAP) (Hwang \& Yoon 1981). However, entropy and LINMAP methods are more suitable to be used when the data of the decision matrix is known. According to Milani et al. (2005), entropy method offers faster solution compared with LINMAP. In this paper, we use Entropy to find out the weights of the evaluation criteria and multi-attributive border approximation area comparison (MABAC) method for performance evaluation (Pamucar \& Cirovic, 2016). The proposed performance model starts with the definition of decision matrix which has in general four components, such as: (i) alternatives (ii) criteria or attributes (iii) subjective weights or relative importance of each criteria and (iv) measure of performance of alternatives with respect to the criteria. The decision matrix can be expressed as follows:

$$
\begin{aligned}
& \begin{array}{lllllll}
C_{1} & C_{2} & . . & C_{j} & . . & C_{n}
\end{array} \\
& \begin{array}{llllll}
W_{1} & W_{2} & . . & W_{j} & . . & W_{n}
\end{array}
\end{aligned}
$$

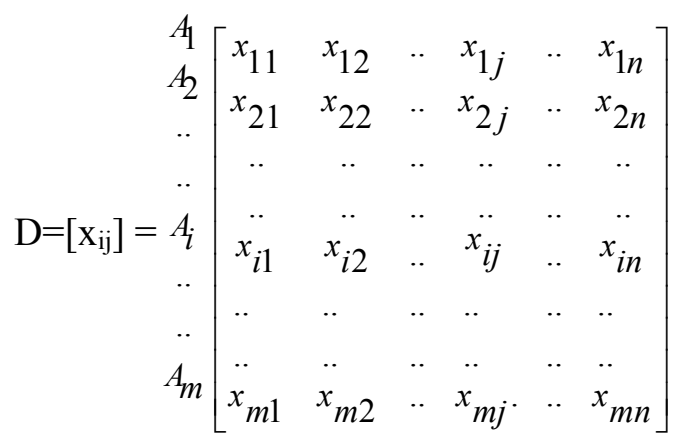


where $A_{\mathrm{i}}$ represents the alternatives, $i=1,2, \ldots, m ; C_{j}$ represents $\mathrm{j}^{\text {th }}$ criterion or attribute, $j=1,2, \ldots$, $n$, related to $\mathrm{i}^{\text {th }}$ alternative. The subjective weight of the $\mathrm{j}^{\text {th }}$ attribute is denoted by $W_{j}$ and $x_{i j}$ indicates the performance of each alternative $A_{i}$ with respect to each criterion $C_{j}$.

\subsubsection{Entropy method for assessing weight}

In this research paper, we applied entropy method because it is highly reliable for information measurement and provide high accuracy in determination of weight of the feature attribute of the product. However, entropy method is more suitable to be used when the data of the decision matrix is known. The entropy formulation is shown in Eq. (2)

$$
E j=-k \sum_{i=1}^{n} p_{i j} \ln p_{i j} \quad j=1,2,3, \ldots \ldots, j \quad i=1,2,3, \ldots \ldots ., n
$$

where,

$$
p_{i j}=\frac{x_{i j}}{\sum_{i=1}^{n} x_{i j}} \quad j=1,2,3, \ldots \ldots, j \quad i=1,2,3, \ldots \ldots ., n
$$

and

$$
k=\frac{1}{\ln n},
$$

where $p_{i j}$ is a discrete probability distribution of the $i^{\text {th }}$ alternative with respect to the $j^{\text {th }}$ attribute. Constant $k$ used to ensure that $0 \leq \mathrm{e}_{\mathrm{j}} \leq 1$.

Degree of divergence, $d_{j}$ can be calculated as:

$$
\mathrm{d}_{\mathrm{j}}=1-\mathrm{Ej} \quad j=1,2,3, \ldots \ldots, j
$$

Final relative weights for $j_{t h}$ attribute can be obtained by simple additive normalization:

$$
w_{j}=\frac{d_{j}}{\sum_{j=1}^{j} d_{j}} \quad j=1,2,3, \ldots \ldots, j
$$

\subsubsection{MABAC method:}

After obtaining the weight coefficients, the conditions are ready to introduce the mathematical formulation of the MABAC method. The basis of the MABAC method is seen in the definition of the distance of the criterion function of each alternative from the border approximation area. The next section shows the process of the MABAC method, consisting of 6 steps:

Step 1.Formation of the initial decision matrix $X=\left[\mathrm{x}_{\mathrm{ij}}\right]_{\mathrm{mxn}}$.

Step 2. Normalize the decision matrix as $\mathrm{N}=\left[\mathrm{n}_{\mathrm{ij}}\right]_{\mathrm{mxn}}$.

The elements of the normalized matrix $(\mathrm{N})$ are determined using the equation:

(a) For Benefit type criteria (a higher value of the criterion is preferable) 


$$
n_{i j}=\frac{x_{i j}-x_{i}^{-}}{x_{i}^{+}-x_{i}^{-}}
$$

(b) For Cost type criteria (a lower value of the criterion is preferable)

$$
n_{i j}=\frac{x_{i j}-x_{i}^{+}}{x_{i}^{-}-x_{i}^{+}},
$$

where, $x_{i j}, x_{i}{ }^{+}$and $x_{i}{ }^{-}$are the elements from the initial decision matrix (X), for which $x_{i}{ }^{+}$and $x_{i}{ }^{-}$are defined as:

$x_{i}^{+}=\max \left(x_{1}, x_{2}, \ldots, x_{m}\right)$ and is the maximum value of the observed criterion according to the alternatives. $x_{i}^{-}=\min \left(x_{1}, x_{2}, \ldots, x_{m}\right)$ and is the minimum value of the observed criterion according to the alternatives.

Step3.Form weighted normalize decision matrix (V). The elements of the weighted normalized matrix (V) are calculated on the basis of the expression

$$
v_{i j}=w_{i} \cdot\left(n_{i j}+1\right)
$$

Step 4.Determining the border approximation area matrix $(\mathrm{G})$. The border approximation area (BAA) for each criterion is determined according to the following equation.

$$
g_{i}=\left(\prod_{j=1}^{m} v_{i j}\right)^{1 / m},
$$

where, $\mathrm{v}_{\mathrm{ij}}$ are the elements of the weighted normalized matrix $(V)$, and $m$ is the total number of alternatives. After calculating the value $g_{i}$ for each criterion, a border approximation area matrix $G=\left[\begin{array}{llll}g_{1} & g_{2} & \ldots & g_{n}\end{array}\right]$ is formed with the format $\mathrm{nx} 1$ (n is the total number of criteria according to which the selection is made from the alternatives offered).

Step 5.Calculation of the distance of the alternative from the border approximation area for the matrix elements as follows,

$$
Q=V-G
$$

The border approximation area $(\mathrm{G})$ is dividing the entire approximation area into two halves as upper approximation area $\left(\mathrm{G}^{+}\right)$and lower approximation area $\left(\mathrm{G}^{-}\right)$. Alternative $\mathrm{A}_{\mathrm{i}}$ may belong to the border approximation area $(\mathrm{G})$ or either of the upper and lower approximation area based on following equation.

$$
A_{i} \in\left\{\begin{array}{ccc}
G^{+} & \text {if } & q_{i j}>1 \\
G & \text { if } & q_{i j}=0 \\
G^{-} & \text {if } & q_{i j}<1
\end{array}\right.
$$

Any alternative $A i$ to be selected as the best in the set, it is necessary for it to have as many criteria as possible belonging to the upper approximate area $\left(\mathrm{G}^{+}\right)$. As for example, if alternative $A_{i}$ has 6 criteria (out of a total of 7 criteria) belonging to the upper approximation area, and one criterion belonging to the lower approximate area $\left(\mathrm{G}^{-}\right)$it means that according to 6 criteria, the alternative is near or equal to the positive ideal alternative, while for one criterion it is near or equal to the negative ideal alternative. If the value $q_{i j}>0$, that is $q_{i j} \epsilon G^{+}$, then alternative $A_{i}$ is near or equal to the positive ideal alternative. If 
the value $q_{i j}<0$, that is $q_{i j} \in G^{-}$, it shows that alternative $\mathrm{A}_{\mathrm{i}}$ is near or equal to the negative ideal alternative.

Step 6.Compute overall score of the alternatives using the following equation.

$$
S_{i}=\sum_{j=1}^{n} q_{i j}
$$

Rank the alternatives based on decending value of $\mathrm{S}_{\mathrm{i}}$.

\section{Application of the proposed model for hybrid vehicle selection}

The proposed entropy-MABAC model for selection of vehicle consists of two basic stages: (i) determination of weight using entropy and (ii) ranking of alternatives using MABAC.

\subsection{Weights of criteria}

In this work, the weights have been computed using an entropy methodology (Eq.2 to Eq. 6) as shown in Fig. 1. The highest weight obtained is 0.3342 which corresponds to base model price and the lowest weight obtained for combined fuel economy which is 0.1406 .

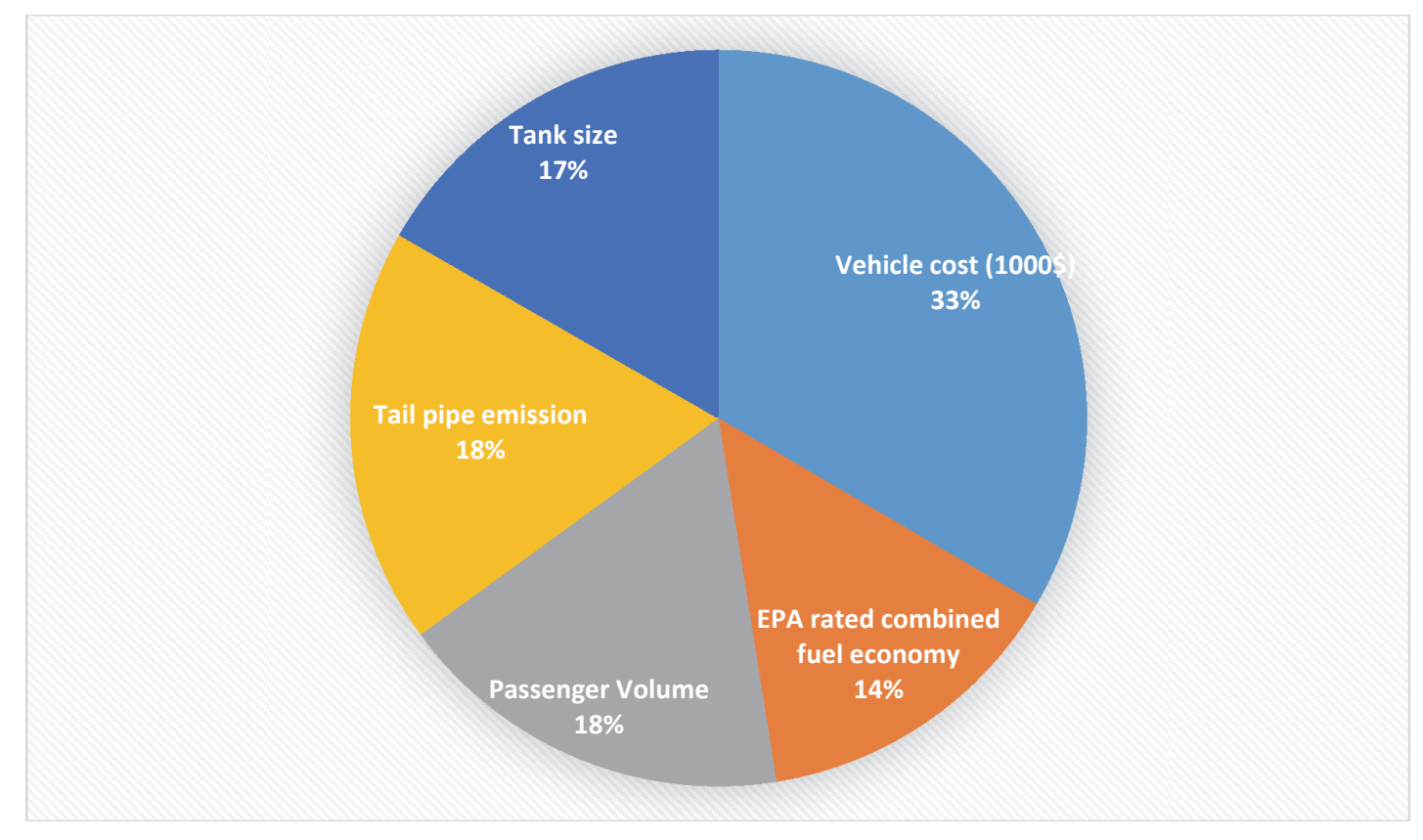

Fig. 1. Entropy based criteria weights.

\subsection{Data and computation}

For the purpose of performance evaluation and ranking of HEVs, nine US models namely Ford C max hybrid plugin, Honda accord hybrid, Honda CR-Z hybrid CVT, Infinity Q70 hybrid, Lexus city hybrid 200 H, Toyota Camry hybrid LE, Toyota Prius, VW Jetta hybrid, Chevy Malibu hybrid have been chosen as alternatives which are coded as HEV1 through HEV9. Their performance against selected criteria is shown in Table 2. The elements of Table 2 have been collected from manufacturers' website. 
Table 2

Quantitative data for performance evaluation

\begin{tabular}{|c|c|c|c|c|c|}
\hline \multirow[b]{2}{*}{ Alternatives } & \multicolumn{5}{|c|}{ Criterion } \\
\hline & $\begin{array}{l}\text { EPA rated combined } \\
\text { fuel economy } \\
\text { (C1) (MPG) }\end{array}$ & $\begin{array}{c}\text { Tank Size } \\
\text { (C2) } \\
\text { (Gal) }\end{array}$ & $\begin{array}{l}\text { Emissions } \\
\text { (C3) } \\
\text { (tons/year) }\end{array}$ & $\begin{array}{c}\text { Passenger Volume } \\
(\mathrm{C} 4) \\
\left(\mathrm{ft}^{3}\right)\end{array}$ & $\begin{array}{c}\text { Base Model Price } \\
\text { (C5) } \\
(1000 \$)\end{array}$ \\
\hline HEV1 & 39 & 13.5 & 3.1 & 100 & 24 \\
\hline HEV2 & 48 & 11 & 4.5 & 103 & 29.6 \\
\hline HEV3 & 36 & 10.6 & 4.3 & 49.1 & 20.295 \\
\hline HEV4 & 30 & 17.8 & 5.1 & 100 & 50 \\
\hline HEV5 & 42 & 11.9 & 3.5 & 86 & 31 \\
\hline HEV6 & 40 & 17.2 & 3.6 & 101 & 26 \\
\hline HEV7 & 56 & 11.9 & 2.8 & 96 & 25 \\
\hline HEV8 & 44 & 11.9 & 3.3 & 94 & 31.12 \\
\hline HEV9 & 46 & 13 & 3.2 & 95 & 28.756 \\
\hline
\end{tabular}

Source: Sources of data are www.fueleconomy.gov and manufacturer Web sites.

The elements of Table 2 are normalized using Eq. (7)-(8). The normalized decision matrix is shown in Table 3.

Table 3

Normalized matrix $\mathrm{N}$

\begin{tabular}{|c|c|c|c|c|c|}
\hline & & & Criterion & & \\
\hline Alternatives & $(\mathrm{C} 1)$ & $(\mathrm{C} 2)$ & (C3) & (C4) & (C5) \\
\hline HEV1 & 0.3461538 & 0.402777778 & 0.869565217 & 0.944341373 & 0.875273523 \\
\hline HEV2 & 0.6923077 & 0.055555556 & 0.260869565 & 1 & 0.686753072 \\
\hline HEV3 & 0.2307692 & 0 & 0.347826087 & 0 & 1 \\
\hline HEV4 & 0 & 1 & 0 & 0.944341373 & 0 \\
\hline HEV 5 & 0.4615385 & 0.180555556 & 0.695652174 & 0.684601113 & 0.639622959 \\
\hline HEV6 & 0.3846154 & 0.916666667 & 0.652173913 & 0.962894249 & 0.80794479 \\
\hline HEV7 & 1 & 0.180555556 & 1 & 0.87012987 & 0.841609157 \\
\hline HEV8 & 0.5384615 & 0.180555556 & 0.782608696 & 0.833024119 & 0.635583235 \\
\hline HEV9 & 0.6153846 & 0.333333333 & 0.826086957 & 0.851576994 & 0.715165797 \\
\hline
\end{tabular}

Then the weighted normalized matrix is computed for all the alternatives according to step 3 of MABAC method. The values are presented in Table 4.

Table 4

Weighted normalized decision matrix $\mathrm{V}$

\begin{tabular}{lccccc}
\hline Alternatives & \multicolumn{5}{c}{ Criterion } \\
\cline { 2 - 6 } & C1 & C2 & C3 & C4 & C5 \\
\hline HEV1 & 0.189269231 & 0.234404167 & 0.342130435 & 0.340454174 & 0.626716411 \\
HEV2 & 0.237938462 & 0.176383333 & 0.23073913 & 0.3502 & 0.563712877 \\
HEV3 & 0.173046154 & 0.1671 & 0.246652174 & 0.1751 & 0.6684 \\
HEV4 & 0.1406 & 0.3342 & 0.183 & 0.340454174 & 0.3342 \\
HEV5 & 0.205492308 & 0.197270833 & 0.310304348 & 0.294973655 & 0.547961993 \\
HEV6 & 0.194676923 & 0.320275 & 0.302347826 & 0.343702783 & 0.604215149 \\
HEV7 & 0.2812 & 0.197270833 & 0.366 & 0.32745974 & 0.61546578 \\
HEV8 & 0.216307692 & 0.197270833 & 0.326217391 & 0.320962523 & 0.546611917 \\
HEV9 & 0.227123077 & 0.2228 & 0.334173913 & 0.324211132 & 0.573208409 \\
\hline
\end{tabular}

By calculating geometric mean (Eq. 10), the border approximation area matrix is obtained and shown in Table 5. 
Table 5

Border approximation area matrix

\begin{tabular}{lccccc}
\hline \multirow{2}{*}{ BBA } & \multicolumn{5}{c}{ Criterion } \\
\cline { 2 - 6 } & $\mathrm{C} 1$ & $\mathrm{C} 2$ & $\mathrm{C} 3$ & $\mathrm{C} 4$ & $\mathrm{C} 5$ \\
\hline $\mathrm{g}_{\mathrm{i}}$ & 0.203764178 & 0.221141521 & 0.287306161 & 0.307462238 & 0.555521737 \\
\hline
\end{tabular}

Now the distance matrix is computed for all the alternatives according to the step 5 of MABAC method. The same is shown in Table 6.Then the distance matrix is developed using Eq.(11). The values are presented in Table 6.

\section{Table 6}

Distance of the alternative from the BAA matrix $(\mathrm{Q})$

\begin{tabular}{lccccc}
\hline \multirow{2}{*}{ Alternatives } & \multicolumn{3}{c}{ Criterion } \\
\cline { 2 - 6 } & $\mathrm{C} 1$ & $\mathrm{C} 2$ & $\mathrm{C} 3$ & $\mathrm{C} 4$ & $\mathrm{C} 5$ \\
\hline HEV1 & -0.01449495 & 0.013262646 & 0.054824274 & 0.032991937 & 0.071194674 \\
HEV2 & 0.034174284 & -0.044758188 & -0.05656703 & 0.042737762 & 0.008191139 \\
HEV3 & -0.03071802 & -0.054041521 & -0.040653987 & -0.132362238 & 0.112878263 \\
HEV4 & -0.06316418 & 0.113058479 & -0.104306161 & 0.032991937 & -0.221321737 \\
HEV5 & 0.00172813 & -0.023870688 & 0.022998187 & -0.012488583 & -0.007559744 \\
HEV6 & -0.00908725 & 0.099133479 & 0.015041665 & 0.036240545 & 0.048693412 \\
HEV7 & 0.077435822 & -0.023870688 & 0.078693839 & 0.019997502 & 0.059944043 \\
HEV8 & 0.012543515 & -0.023870688 & 0.038911231 & 0.013500285 & -0.00890982 \\
HEV9 & 0.023358899 & 0.001658479 & 0.046867752 & 0.016748894 & 0.017686672 \\
\hline
\end{tabular}

Lastly the overall score (Si) of alternatives are calculated using Eq.(12). Table7 exhibits EntropyMABAC based performance score and relative rank of the alternatives.

Table 7

Entropy-MABAC based performance score and relative rank of the alternatives

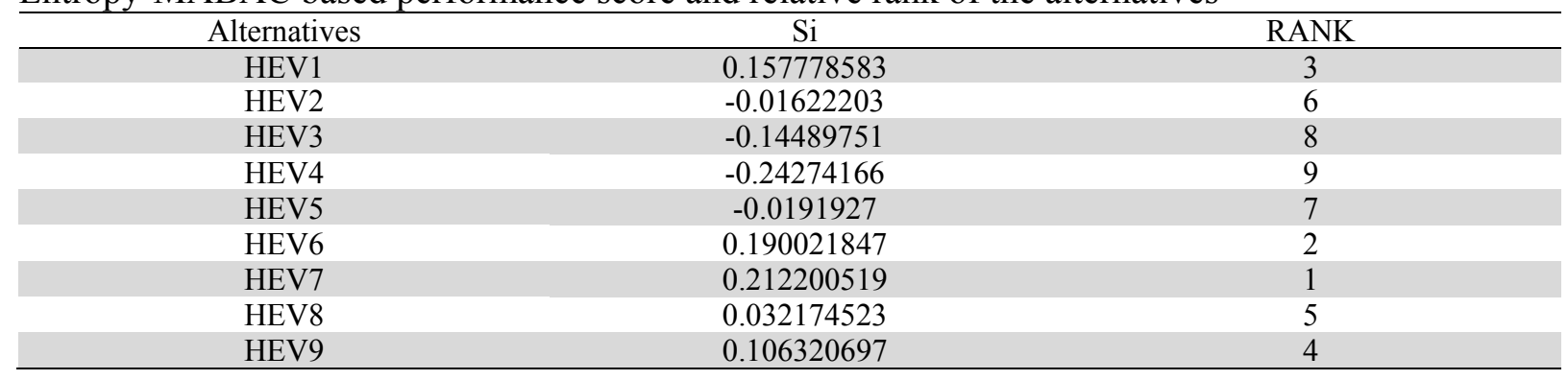

\section{Discussion}

Selection of appropriate HEV for the customer is an interactive task because of conflicting attributes. The hybrid model consisting of Entropy and MABAC has been proven to render an effective decision to evaluate HEV under requirement perspective of customer. This approach is fit for supporting the decision-makers due to the following benefits. The impact of the interactions between the attributes is considered in the Entropy method when determining the weights of the attributes (Fig.1). Lastly, the MABAC method used to obtain the ranking of alternatives (Table 7).

It is evident from decision matrix that HEV7 outperforms in respect of combined fuel economy in comparison to other alternatives. Good fuel economy is one of the indicators of most energy efficient car. This model achieve better fuel economy and have lower fuel cost than similar vehicles i.e. reduces the running cost of the vehicle. The performance of HEV3 and HEV4 is not significant in this criterion. Another important criterion is engine emission which ultimately increases the global warming. In this 
respect, HEV7 possesses 2.8 tons per year emission whereas HEV4 is having 5.1 tons per year. The starting price of HEV7 is fairly low compare to HEV4 or HEV5. Therefore, in all respect HEV7 is performing best. However, it is also observed in sensitivity plot (Fig.2) that this vehicle holds first rank almost all the cases. For anyone looking at a low cost HEV, the HEV7 should be best for given attribute.

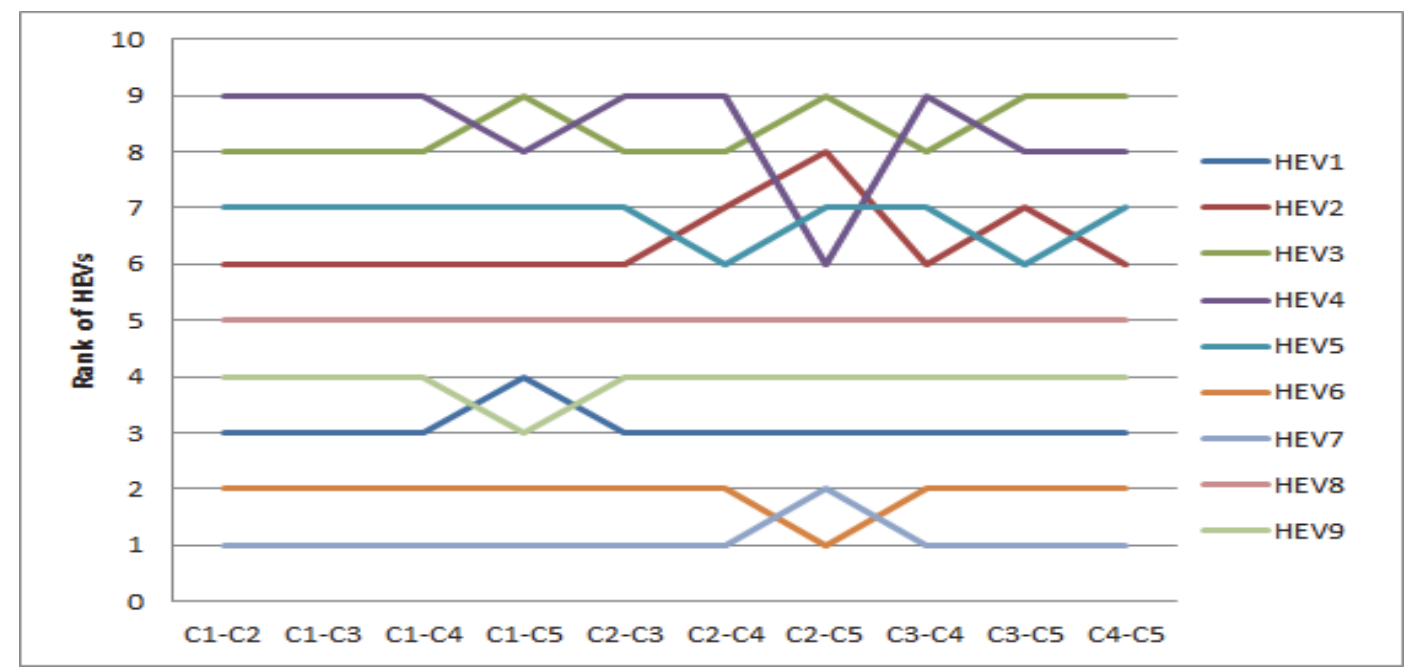

\section{Conclusion}

Fig. 2. Sensitivity plot

The proposed model for hybrid electric vehicles selection has dealt with finding of the best HEV among available alternatives in passenger car segment. After checking the various process parameters under different circumstances, it has observed that the proposed model is simple to use and easy to understand. Also, the computational time requirement is less and the stability of result obtained is high. Finally, a sensitivity analysis has shown to confirm the robustness of the ranking and further support the decision when selecting the final result. As the proposed Entropy-MABAC model is robust, the number of alternatives and evaluation criteria in the decision matrix can be increased to get a more effective decision. This study can be extended for similar exercises in commercial vehicle, sports utility vehicle, multi utility vehicle segments. As the proposed model is generic in nature, it can be used for performance evaluation and ranking in other sectors of the society at large.

\section{References}

Al-Samari, A. (2017). Study of emissions and fuel economy for parallel hybrid versus conventional vehicles on real world and standard driving cycles. Alexandria Engineering Journal.

Beresteanu, A., \& Li, S. (2011). Gasoline prices, government support, and the demand for hybrid vehicles in the United States. International Economic Review, 52(1), 161-182.

Bradley, T. H., \& Frank, A. A. (2009).Design, demonstrations and sustainability impact assessments for plug-in hybrid electric vehicles. Renewable and Sustainable Energy Reviews, 13(1), 115-128.

Chandra, A., Gulati, S., \& Kandlikar, M. (2010).Green drivers or free riders? An analysis of tax rebates for hybrid vehicles. Journal of Environmental Economics and management, 60(2), 78-93.

Gallagher, K. S., \& Muehlegger, E. (2011). Giving green to get green? Incentives and consumer adoption of hybrid vehicle technology. Journal of Environmental Economics and management, 61(1), 115.

Ganji, B., Kouzani, A. Z., \& Trinh, H. M. (2010). Drive cycle analysis of the performance of hybrid electric vehicles. In Life system modeling and intelligent computing (pp. 434-444).Springer, Berlin, Heidelberg. 
De Haan, P., Mueller, M. G., \& Peters, A. (2006). Does the hybrid Toyota Prius lead to rebound effects? Analysis of size and number of cars previously owned by Swiss Prius buyers. Ecological Economics, 58(3), 592-605.

Hwang, C. L.,\& Yoon, K. (1981). Multiple Attribute Decision Making: Methods and Applications A State-of-the-ArtSurvey,SpringerBerlin Heidelberg.

Kahn, M. E. (2007). Do greens drive Hummers or hybrids? Environmental ideology as a determinant of consumer choice. Journal of Environmental Economics and Management, 54(2), 129-145.

Milani, A. S., Shanian, A., Madoliat, R., \& Nemes, J. A. (2005). The effect of normalization norms in multiple attribute decision making models: a case study in gear material selection. Structural and multidisciplinary optimization, 29(4), 312-318.

Morrow, K., Karner, D.,\& Francfort, J. (2008).Plug-in Hybrid Electric Vehicle Charging Infrastructure Review, US Department of Energy-Vehicle Technologies Program.

Pamučar, D., \& Ćirović, G. (2015). The selection of transport and handling resources in logistics centers using Multi-Attributive Border Approximation area Comparison (MABAC). Expert Systems with Applications, 42(6), 3016-3028.

Rahman, I., Vasant, P. M., Singh, B. S. M., \& Abdullah-Al-Wadud, M. (2016).On the performance of accelerated particle swarm optimization for charging plug-in hybrid electric vehicles. Alexandria Engineering Journal, 55(1), 419-426.

Sallee, J. M. (2011). The surprising incidence of tax credits for the Toyota Prius. American Economic Journal: Economic Policy, 3(2), 189-219.

Wirasingha, S. G., \& Emadi, A. (2011).Classification and review of control strategies for plug-in hybrid electric vehicles. IEEE Transactions on vehicular technology, 60(1), 111-122.

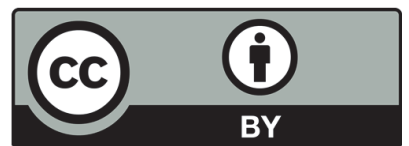

(C) 2018 by the authors; licensee Growing Science, Canada. This is an open access article distributed under the terms and conditions of the Creative Commons Attribution (CC-BY) license (http://creativecommons.org/licenses/by/4.0/). 